\title{
Missing equation in Piketty's r-g theory
}

\author{
Yasunori Fujita* \\ Keio University, Japan
}

Received: 25 February 2015

Revised: 26 June 2015

Accepted: 29 June 2015

\begin{abstract}
Although Thomas Piketty has revolutionized our understanding of inequality, logic behind his $r-g$ theory is not developed formally in his researches. The present paper, by finding out the missing part of Piketty's $r-g$ theory, attempts to construct a model to show the condition where $\beta$ (capital/income ratio) increases over time when $r$ (rate of return on capital) is greater than $g$ (growth rate of output). It is revealed that necessary and sufficient condition for the $r$ - $g$ theory is $S_{Y}(t)=C_{F}(t)$. That is, savings (left hand side) are equal to the consumption using financial capital (right hand side). We also reveal that the problem is not in the Second Fundamental Law of Capitalism, but in the formulation of capital accumulation dynamics. Furthermore, it is demonstrated that the two Fundamental Laws of Capitalism are not necessary for deriving the $r-g$ theory.
\end{abstract}

Keywords: Second Fundamental Law of Capitalism, capital accumulation, inequality JEL Classification Codes: D31, E10, O20, P10

\section{Introduction}

Our understanding of inequality has been changed drastically by Thomas Piketty's extensive studies that connect wealth concentration to the $r>g$ inequality, where $r$ and $g$ denote rate of return on capital and growth rate of output, respectively (Alvaredo, Atkinson, Piketty, and Saez (2013), Piketty (2011, 2014, 2015), Piketty and Saez (2003, 2014), Piketty and Zucman (2014) etc.). Since Piketty and his associates, overviewing Marx (1867) and Kuznets (1955), shed new light on the huge amount of studies of economic growth, their influence has been running deep as Paul Krugman mentions $(2014 a, b)$. In fact, according to Jones (2015), Piketty is so popular that the algebra $r>g$ is seen even on T-shirts.

Despite this "Piketty Panic", underlying logic behind the $r-g$ theory is not developed formally in his researches. It is true that Piketty shows that coefficient of Pareto distributions measuring inequality is an increasing function of the gap $r$-g (Atkinson, Piketty and Saez (2011)) and, of

*E-mail: yfujita@econ.keio.ac.jp.

Citation: Fujita, Y. (2015) Missing equation in Piketty's r-g theory, Economics and Business Letters, 4(2), 57-62. 
course, Pareto distribution is widely utilized to analyze the inequality (Atkinson and Harrison (1978), Stiglitz (1969) and Jones (2015)). It would be, however, better to prove the $r$ - $g$ theory in relation to the capital/income ratio $\beta$, the most important variable in Piketty's framework that expresses the income-wealth-inequality. In other words, since Piketty's $r$ - $g$ theory demonstrates that capitalism generates inequalities (i.e. increases $\beta$ ) when $r$ exceeds $g$, what is necessary is to construct a model where $\beta$ increases over time when $r$ is greater than $g$. In Piketty's recent seminal work (Piketty (2014)) also, although importance of the capital/income ratio $\beta$ and the gap $r$ - $g$ is shown respectively in FIGURE I.2. (The capital/income ratio in Europe, 1870-2010) and FIGURE 10.9. (Rate of return versus growth rate at the world level, from Antiquity until 2100), these two figures are not explained within the context of their relationship.

As is shown in section 3 (Capital Accumulation Dynamics and the r-g Theory), if we postulate the Second Fundamental Law of Capitalism and capital accumulation dynamics as in most of the works of Piketty and his colleagues (Piketty (2014) etc.), derivative of $\beta$ with respect to time turns out to be zero (i.e. the capital/income ratio remains constant over time) for every $r$ and $g$, which, however, is not what the $r$ - $g$ theory should be. Thus, we have to admit something is missing in Piketty's way of analyzing.

In what follows, by finding out the missing part of the $r$ - $g$ theory and dividing the capital into two categories (i.e. real capital and financial capital), we try to construct a model, to show the condition where $\beta$ increases over time when $r$ is greater than $g$. As we will see, main issue stems from the differentiation between real and financial capital. It is revealed that necessary and sufficient condition for the $r$ - $g$ theory is $S_{Y}(t)=C_{F}(t)$. That is, savings (left hand side) are equal to the consumption using financial capital (right hand side). It is also revealed that the problem is not in the Second Fundamental Law of Capitalism, which has been subjected to severe criticism (Krusell and Smith (2014)), but in the formulation of capital accumulation dynamics. Furthermore, it is demonstrated that the two Fundamental Laws of Capitalism are not necessary for deriving the $r-g$ theory.

There have been some papers dealing extensively with the $r>g$ inequality. Bernardo, Martínez and Stockhammer (2014) examine if $r>g$ is necessarily associated with increasing inequality, while Rowthorn (2014) investigate if the rising income share of wealth-owners is due to the over-accumulation of capital. Dumenil and Levy (2014), paying attention to the definition of capital and focusing on fixed capital, analyze if the existence of a tendency toward the gradual concentration of wealth in capitalism is likely or not.

By constructing a simple theoretical model, we attempt to shed new light on this field.

\section{Basic model}

A controversial aspect of Capital in the 21st Century is Piketty's definition of capital itself. So, let us start with the definition of capital.

According to Piketty, capital is defined as total sum of nonhuman assets that can be owned and exchanged on markets, which include all forms of real capital and financial capital. In Piketty's formulation, however, distinction of these two types of capital is ambiguous. As is often the case with Piketty's studies (Alvaredo, Atkinson, Piketty, and Saez (2013), Piketty $(2011,2015)$ etc.), Capital in the 21st Century defines the capital/income ratio $\beta$ as $K / Y$ and, at the same time, formulates process of production as a function of capital $K$ and labor $L$ (e.g. Cobb-Douglas production function, $Y=K^{\alpha} L^{1-\alpha}$, where $\alpha$ is a positive parameter). This formulation, coupled with 
that fact that amount of production is equal to national income in standard macroeconomics (Keynes (1936), Samuelson (1948), etc.) implies immediately that all the capital is used directly for production, which is not proper representation of Piketty's definition that includes financial capital, since financial capital is not directly employed in the production process.

In the following, in order to formulate Piketty's definition, we explicitly divide the capital into two categories:

(1) real capital (capital that is employed in the production process);

(2) financial capital (capital that is not employed in the production process).

Let us assume that real capital of size $K(t-1)$ in period $t$-1 produces goods and services in period $t, Y(t)$, which is equal to national income in period $t$. We also assume that in period $t$, the national income of size $Y(t)$ is used either for consumption, $C_{Y}(t)$ or savings for accumulation of real capital, $S_{Y}(t)$.

The above allocation of national income is expressed as

$$
Y(t)=C_{Y}(t)+S_{Y}(t)
$$

Let us also assume financial capital in period $t-1, F(t-1)$, becomes $(1+r) F(t-1)$ in period $t$, which is used in period $t$ either for consumption, $C_{F}(t)$, savings for accumulation of real capital, $S_{F}(t)$, or demand for financial capital, $F(t)$. Throughout this paper, for the simplicity of analysis, we treat $r$ as an exogenous parameter.

We can express the above allocation of capital income as

$$
(1+r) F(t-1)=C_{F}(t)+S_{F}(t)+F(t)
$$

\section{Capital accumulation dynamics and the $r$ - $g$ theory}

We assume that real capital in period $t-1, K(t-1)$, plus savings becomes the real capital in the next period and $K(t-1)$ is held through corporate shares, which is counted as financial capital. If we let $F_{k}(t-1)$ denote the financial capital through which $K(t-1)$ is held, it follows that $K(t-1)=F_{k}(t-1)$. Therefore, the total sum of capital in period $t$ becomes $K(t)+F(t)-F_{k}(t-1)$ since $K(t-1)$ and $F_{k}(t-1)$ are double counted.

If we assume real capital does not depreciate as in most of Piketty's studies (Piketty (2014) etc.) accumulation dynamics of real capital is expressed as

$$
K(t)=K(t-1)+S_{Y}(t)+S_{F}(t)
$$

As for accumulation dynamics of financial capital, on the other hand, we have

$$
F(t)=(1+r) F(t-1)-C_{F}(t)-S_{F}(t)
$$

directly from (2). Therefore, if we let $W(t)$ denote the total sum of capital in period $t$, we obtain its accumulation dynamics as

$$
W(t)=(1+r) W(t-1)+S_{Y}(t)-C_{F}(t),
$$

which reduces to the following derivative of $W$ with respect to time, $t$ 


$$
\frac{d W(t)}{d t}=r W(t)+S_{Y}(t)-C_{F}(t)
$$

by assuming continuous time horizon for the simplicity of analysis.

Substituting (6) and the definition of $g\left(\equiv \frac{\frac{d Y(t)}{d t}}{Y(t)}\right)$ into the derivative of $\beta\left(\equiv \frac{W(t)}{Y(t)}\right)$ (i.e. $\frac{d \beta}{d t}=\frac{\frac{d W(t)}{d t} Y(t)-W(t) \frac{d Y(t)}{d t}}{\{Y(t)\}^{2}}$, we have the dynamics of the capital/income ratio $\beta$ as

$$
\frac{d \beta}{d t}=\frac{1}{Y(t)}\left\{(r-g) W(t)+S_{Y}(t)-C_{F}(t)\right\} .
$$

This equation, the missing part of the $r-g$ theory, enables us to derive the condition where $\beta$ increases over time when $r$ is greater than $g$.

\section{Proposition:}

Necessary and sufficient condition for the r-g theory is $S_{Y}(t)=C_{F}(t)$.

Here, the $r$ - $g$ theory is defined as a theory that states $\beta$ increases over time when $r$ is greater than $g$.

Since $S_{Y}(t)$ is savings, we can say that $S_{Y}(t)=C_{F}(t)$ describes a situation where savings (left hand side) are equal to the consumption using financial capital (right hand side).

More understandable situation for $S_{Y}(t)=C_{F}(t)$ is $S_{Y}(t)=C_{F}(t)=0$. Since $S_{Y}(t)=Y(t)-C_{Y}(t)$ holds by the above allocation of national income, $S_{Y}(t)=0$ is equivalent to $Y(t)=C_{Y}(t)$, which implies that $S_{Y}(t)=C_{F}(t)=0$ is a situation where all the national income is used for consumption, while no income from the financial capital is used for consumption.

Note that if we assume, as in Piketty (2014) etc., $W=K$ (i.e. financial capital is assumed away), $\beta \equiv \frac{K}{Y}=\frac{s}{g}$, where $s$ stand for savings rate (i.e. the Second Fundamental Law of Capitalism) and $\frac{d K}{d t}=s Y \quad$ (i.e. capital accumulation dynamics), it follows that $\frac{d \beta}{d t}=\frac{d K(t)}{d t} \frac{1}{Y(t)}-\frac{K(t)}{Y(t)} \frac{\frac{d Y(t)}{d t}}{Y(t)}=s Y(t) \frac{1}{Y(t)}-\frac{s}{g} g=0$.

It also follows from (7) that if $S_{Y}(t)>C_{F}(t), r>g$ is a sufficient condition (not a necessary condition) for $\frac{d \beta}{d t}>0$. Since $S_{Y}(t)=Y(t)-C_{Y}(t)$ as we mentioned above, $S_{Y}(t)>C_{F}(t)$ is equivalent 
to $Y(t)>C_{Y}(t)+C_{F}(t)$, which means that the output is greater than the total consumption. Since this condition always holds if we presume a closed economy or the world economy as a whole, we have the following corollary.

\section{Corollary:}

In a closed economy or in the world as a whole, $\frac{d \beta}{d t}>0$ holds if $r>g$.

López-Bernardo et al. (2014) showed that a constant capital-output ratio and even a decreasing one is perfectly compatible with $r>g$ within a framework of Cambridge model. From (7), we can say that $\frac{d \beta}{d t}=0$ and $r>g$ if $(r-g) W(t)=C_{F}(t)-S_{Y}(t)$ and $\frac{d \beta}{d t}<0$ and $r>g$ if $(r-g) W(t)<C_{F}(t)-$ $S_{Y}(t)$, which is consistent with López Bernardo et al. (2014). This corollary, however, shows that in a closed economy or in the world as a whole, unlike López Bernardo et al. (2014), a constant capital-output ratio or a decreasing one is not compatible with $r>g$.

\section{Conclusion}

We began this research with the hope of showing the condition where $\beta$ increases over time when $r$ is greater than $g$. Our results were more surprising than we had hoped: the two Fundamental Laws of Capitalism, which are two of the most essential formulas in Piketty's economics, are not necessary for deriving the $r$ - $g$ theory, and the $r$ - $g$ theory remains intact as a sufficient condition.

A great deal of controversy has been provoked by Piketty's economics (Milanovic, 2014). We truly hope this research note, which finds out the missing part of the $r$ - $g$ theory, will contribute to better understanding of the new and rich framework Thomas Piketty has provided.

Acknowledgments. The author would like to thank the three anonymous reviewers for their valuable comments and suggestions to improve the quality of the paper.

\section{References}

Alvaredo, F., Atkinson, A.B., Piketty, T. and Saez, E. (2013) The top 1 percent in international and historical perspective, Journal of Economic Perspectives, 27(3), 3-20.

Atkinson, A.B. and Harrison, A.J. (1978) Distribution of personal wealth in Britain, 1923-1972, Cambridge University Press, Cambridge.

Atkinson, A.B., Piketty, T. and Saez, E. (2011) Top incomes in the long run of history, Journal of Economic Literature, 49, 3-71.

López-Bernardo, J., López-Martínez, F. and Stockhammer, E. (2014) A post-Keynesian response to Piketty's "Fundamental Contradiction of Capitalism", Post Keynesian Economics Study Group, Working Paper 1411.

Jones, C.I. (2015) Pareto and Piketty: the macroeconomics of top income and wealth inequality, Journal of Economic Perspectives, 29(1), 29-46. 
Dumenil, G. and Levy, D. (2014) Thomas Piketty's economics: modeling wealth and wealth inequality, EconomiX, PSE: Paris.

Keynes, J.M. (1936) The General Theory of Employment, Interest and Money, Macmillan, London.

Krugman, P. (2014a) The Piketty panic, The New York Times, April 24.

Krugman, P. (2014b) Why we're in a new gilded age, New York Review of Books, May 8.

Krusell, P. and Smith, T. (2014) Is Piketty's "Second Law of Capitalism" Fundamental?, mimeo.

Kuznets, S. (1955) Economic growth and income inequality, American Economic Review, 45(1), $1-28$.

Marx, K. (1867) Capital, translated by A. Moore and E. Aveling, International Publisher, New York.

Milanovic, B. (2014) The return of "Patrimonial Capitalism": a review of Thomas Piketty's Capital in the Twenty-First Century, Journal of Economic Literature, 52(2), 519-534.

Piketty, T. and Saez, E. (2003) Income inequality in the United States, 1913-1998, Quarterly Journal of Economics, 118(1), 1-39.

Piketty, T. (2011) On the long-run evolution of inheritance: France 1820-2050, Quarterly Journal of Economics, 126(3), 1071-1131.

Piketty, T. (2014) Capital in the Twenty-First Century, translated by Arthur Goldhammer, Belknap Press.

Piketty, T. (2015) Putting distribution back at the center of Economics: reflections on Capital in the Twenty-First Century, Journal of Economic Perspectives, 29(1), 67-88.

Piketty, T. and Saez, E. (2014) Inequality in the long run, Science, 344, 838-844.

Piketty, T. and Zucman, G. (2014) Capital is back: wealth-income ratios in rich countries 1700-2010, Quarterly Journal of Economics, 129(3), 1255-1310.

Rowthorn, R. (2014) A note on Piketty's Capital in the Twenty-First Century, Cambridge Journal of Economics, 38, 1275-1284.

Samuelson, P.A.(1948) Economics: An Introductory Analysis, McGraw-Hill, New York.

Stiglitz, J.E. (1969) Distribution of income and wealth among individuals, Econometrica, 37, 382-397. 